\title{
The Use of Galleria mellonella Larvae to Identify Novel Antimicrobial Agents against Fungal Species of Medical Interest
}

\author{
Kevin Kavanagh * and Gerard Sheehan \\ Medical Mycology Laboratory, Department of Biology, Maynooth University, Maynooth, Co. Kildare W23F2H6, \\ Ireland; gerard.sheehan.2103@mumail.com \\ * Correspondence: kevin.kavanagh@mu.ie
}

Received: 29 August 2018; Accepted: 15 September 2018; Published: 19 September 2018

\begin{abstract}
The immune system of insects and the innate immune response of mammals share many similarities and, as a result, insects may be used to assess the virulence of fungal pathogens and give results similar to those from mammals. Larvae of the greater wax moth Galleria mellonella are widely used in this capacity and also for assessing the toxicity and in vivo efficacy of antifungal drugs. G. mellonella larvae are easy to use, inexpensive to purchase and house, and have none of the legal/ethical restrictions that are associated with use of mammals. Larvae may be inoculated by intra-hemocoel injection or by force-feeding. Larvae can be used to assess the in vivo toxicity of antifungal drugs using a variety of cellular, proteomic, and molecular techniques. Larvae have also been used to identify the optimum combinations of antifungal drugs for use in the treatment of recalcitrant fungal infections in mammals. The introduction of foreign material into the hemocoel of larvae can induce an immune priming effect which may operate independently with the activity of the antifungal drug. Procedures to identify this effect and limit its action are required.
\end{abstract}

Keywords: Galleria; model organism; antifungal; in vivo testing; immunomodulatory

\section{Advantages of Galleria mellonella Larvae}

The insect immune response displays many structural and functional similarities to the innate immune response of mammals [1]. For example, insect hemocytes show many similarities (e.g., phagocytosis, superoxide production) to mammalian phagocytes [2] and many of the receptors (e.g., Toll) and response pathways (e.g., coagulation and melanisation) in insects are comparable to those in mammals [1,3]. Due to the presence of these conserved features, insects are now widely used to assess the virulence of fungal pathogens and to determine the toxicity and in vivo efficacy of novel and conventional antifungal drugs and produce results comparable to those that may be obtained using mammals.

A wide range of insects is now used as in vivo models (e.g., Drosophila melanogaster, Manduca sexta, Bombyx mori) $[4,5]$ but larvae of the Greater wax moth (Galleria mellonella) are a popular choice due to their ease of inoculation, low cost and the ability to generate results in 24-48 $\mathrm{h}[6,7]$ (Figure 1). The low cost of larvae means it is possible to perform many replicates and produce statistically valid results. G. mellonella larvae are easy to house and their use has none of the legal or ethical constraints that restrict the use of mammals. Larvae are amenable to incubation at $37^{\circ} \mathrm{C}$ which means that many temperature dependent virulence factors of human pathogens are active. In addition, G. mellonella larvae may be easily and accurately inoculated via intra-hemocoel injection (Figure 2A,B), by force-feeding or by rolling on a layer of spores and a number of parameters may be employed to assess their response to infection. These include mortality, extent of melanization, alteration in hemocyte density and/or 
function, changes in microbial load, formation of pupa, movement, alteration in gene expression and variations in the proteome. Another advantage is that due to their size and ease of handling it is possible to administer a defined inoculum by force-feeding or intra-hemocoel injection to larvae. Larvae can be used for pharmacokinetic and pharmacodynamics studies and larvae produce a large volume (80-100 $\mu \mathrm{L} /$ larva) of hemolymph (Figure 2C) (analogous to mammalian blood) which can be analysed by a variety of methods [8-10]. Hemocytes (immune cells) can be isolated from larvae and subjected to a range of ex vivo cellular assays in response to microbial pathogens and/or to determine the effect of chemical agents [11-14]. The use of G. mellonella larvae, as with any model organism, has some disadvantages. For example, a lack of mutant strains and larvae may not be a suitable model for some microbial species. However many of the disadvantages detailed by Tsai et al. (2016) have been addressed in the recent past [15-17].

The immune responses of larvae have been recently documented at the proteomic, transcriptomic and epigenetic level due to advances in technologies such as label-free proteomics and miRNAs and the recent sequencing of the G. mellonella genome opens new avenues of research $[16,18,19]$. Although larvae do not possess an adaptive immune response associated with long-lived memory cells and antibodies, they possess immunological memory as evidenced by immune priming resulting in protection against a lethal infection if initially pre-exposed to a low level of the pathogen. The absence of an adaptive response can be an advantage as it allows the researcher to study in detail the interactions of pathogen and the innate immune response without interference from the adaptive response [20].

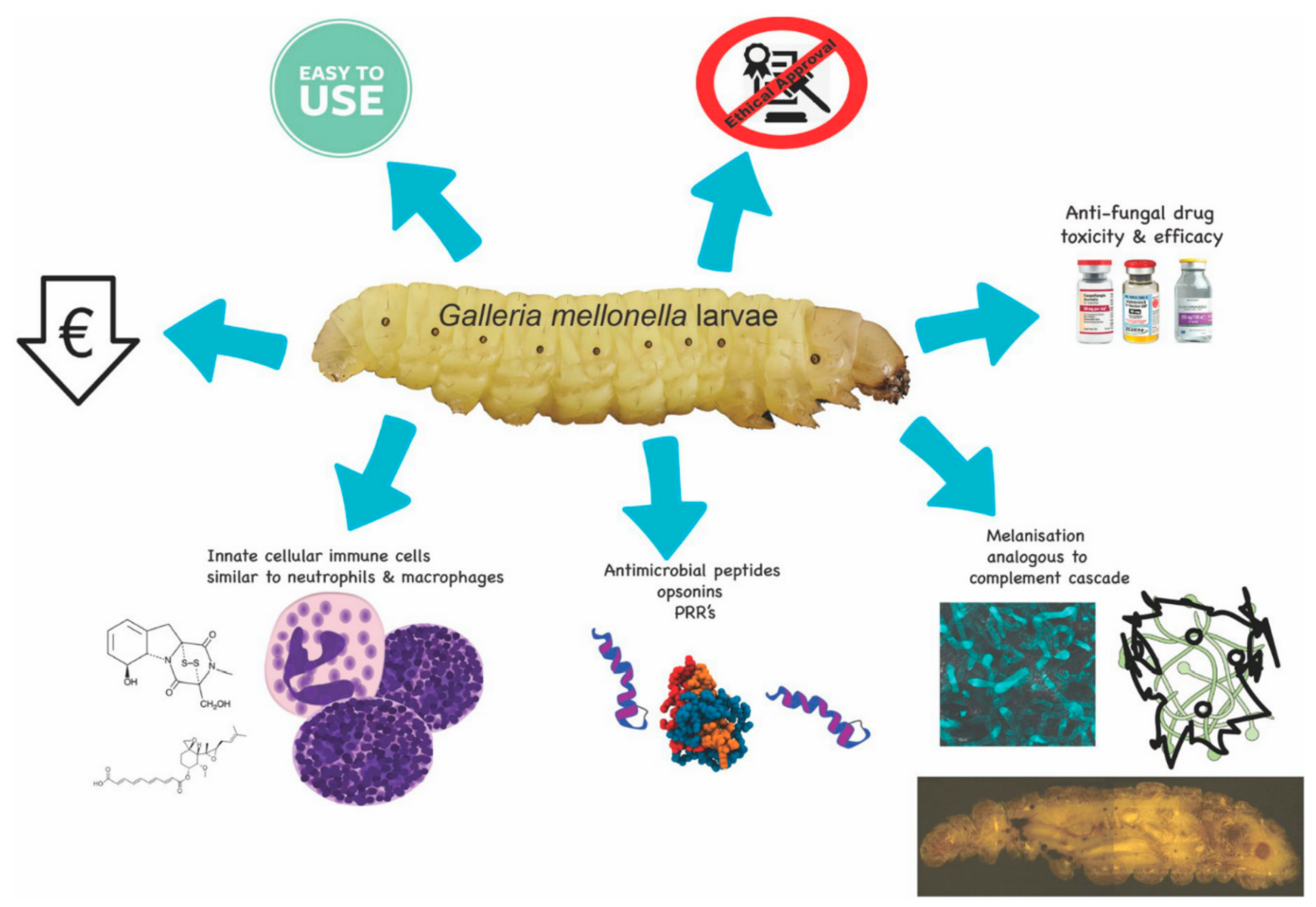

Figure 1. Schematic diagram of some of the advantages associated with using G. mellonella larvae. Larvae are inexpensive to purchase, easy to use, are not subject to the ethical or lethal restrictions associated with mammalian testing, and can be employed for testing the toxicity and efficacy of a range of novel antifungal drugs. These advantages are possible due to the similarities between the mammalian innate immune response and the insect immune system. 


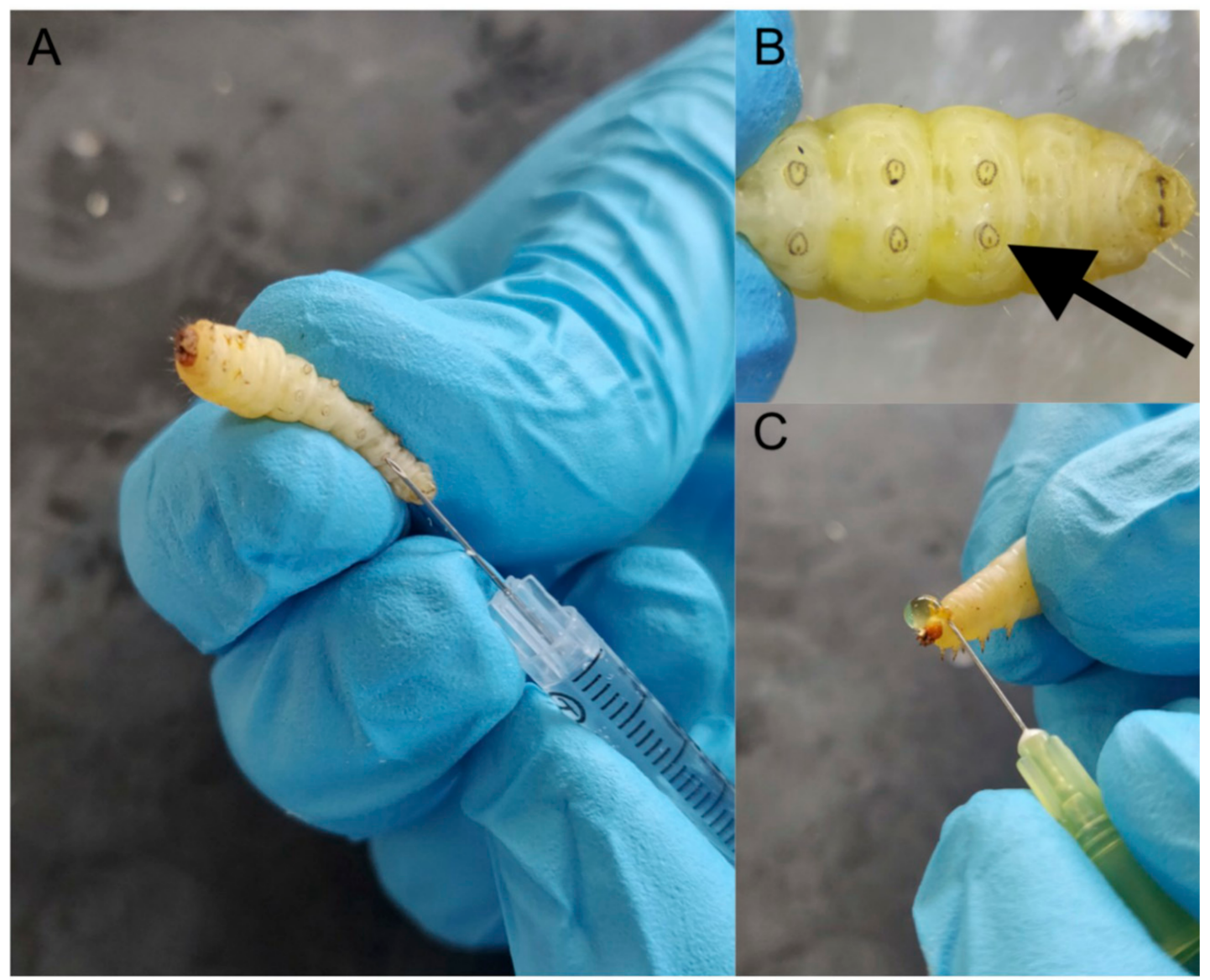

Figure 2. General procedures associated with using G. mellonella larvae. Larvae are inoculated with a specific volume (e.g., $20 \mu \mathrm{L}$ ) through the last left proleg using a syringe (A), magnified image of last left proleg (B), demonstration of the method to obtain hemolymph from larvae (C).

The response of G. mellonella larvae to infection with Candida albicans [21,22] and Aspergillus fumigatus [23-25] shows a strong correlation to the results obtained using mice (Table 1). G. mellonella larvae are excellent models to study the virulence of Candida species [26] and larvae have been utilized to develop an infection model for Cryptococcus neoformans [27,28]. Invertebrates such as Acanthamoeba castellanii, Caenorhabditis elegans, Dictyostelium discoideum, D. melanogaster and G. mellonella, have been employed to characterize the molecular mechanisms which Cryptococcus neoformans utilizes to attack the host [29]. The results revealed that several virulence-related genes previously associated with C. neoformans virulence in mammals also played a role in establishing infection in G. mellonella. C. neoformans serially passaged in G. mellonella larvae showed an enhanced ability to kill mice if administered by intra-tracheal or intravenous route, although their ability to kill G. mellonella larvae remained unchanged. In addition, microarray analysis showed passaged cells had increased expression of genes involved in the oxidative stress response (e.g., peroxiredoxin (Tsa1) Super oxide dismutase (Sod2) [30].

Table 1. Selected examples of utilization of G. mellonella larvae to assess fungal virulence.

\begin{tabular}{cc}
\hline Reference & Fungal Virulence and Infection \\
\hline Brennan et al. 2002 [22] & The virulence of Candida albicans mutants correlates between mice and \\
Galleria mellonella larvae
\end{tabular}


Table 1. Cont.

\begin{tabular}{|c|c|}
\hline Reference & Fungal Virulence and Infection \\
\hline Mesa-Arango et al. 2013 [31] & $\begin{array}{c}\text { Galleria mellonella to study the virulence of the Candida tropicalis and } \\
\text { determine antifungal drug efficacy }\end{array}$ \\
\hline Borman et al. 2016 [32] & Virulence of Candida auris and other Candida spp. In Galleria mellonella \\
\hline Reeves et al. 2004 [24] & $\begin{array}{l}\text { Gliotoxin Production and Virulence of Aspergillus fumigatus in } \\
\text { Galleria mellonella }\end{array}$ \\
\hline Slater et al. 2011 [23] & $\begin{array}{c}\text { Pathogenicity of Aspergillus fumigatus mutants in Galleria mellonella matches } \\
\text { that in mice }\end{array}$ \\
\hline St. Leger et al. 2000 [33] & Aspergillus flavus pathogenicity in Galleria mellonella \\
\hline Navarro-Velasco et al. 2011 [34] & Galleria mellonella to study Fusarium oxysporum mutants. \\
\hline Maurer et al. 2015 [35] & $\begin{array}{c}\text { Galleria mellonella to assess infection, virulence and and amphotericin B } \\
\text { resistance of Aspergillus terreus }\end{array}$ \\
\hline Thomaz et al. 2013 [36] & Galleria mellonella to study Paracoccidioides lutzii and Histoplasma capsulatum \\
\hline
\end{tabular}

G. mellonella larvae can also be used to model the development of systemic Candidosis and Aspergillosis and show many pathologies also found in systemic infection in mammals. Larvae infected with $C$. albicans showed changes similar to those observed in mice challenged with the same pathogen, such as alterations in immune cell density, increased abundance of antimicrobial peptides, and in proteins indicative of tissue invasion [19]. In the case of A. fumigatus infected larvae there is the development of nodules containing viable fungal mycelia and hemocytes, and these are similar in composition to the fungal granulomas found in systemic A. fumigatus infection in mammals [37]. A. fumigatus conidia germinate, form hyphae at the point of inoculation, and invade through larval tissue to produce disseminated aspergillosis, and this shows similarities to the process in mice. The ability to model disease processes in larvae creates the possibility of characterizing the efficacy of antifungal therapy both in terms of larval survival but also in the reduction of the symptoms associated with infection.

\section{Utilization of G. mellonella Larvae for Measuring Relative Toxicity In Vivo}

Insects may be used to assess the relative toxicity of a variety of agents, including antifungal agents, and the results show a strong correlation to those obtained using mammals [38]. In one case G. mellonella larvae were administered, by intra-haemocoel injection or by force-feeding, a variety of food additives and the $\mathrm{LD}_{50}$ values were determined [38]. The values obtained showed a strong correlation to the $\mathrm{LD}_{50}$ values determined in rats. Administration of a wide range of compounds to larvae by intra-hemocoel injection allowed differentiation of the compounds based on relative toxicity and this correlated well with the toxicity as assessed in cell culture systems and in mammals [39]. A strong correlation between the $\mathrm{LD}_{50}$ values of a range of chemicals (e.g., 4-methyl umbelliferone, umbelliferone, and 7-ethoxycoumarine) in silkworm larvae (Bombyx mori) and in mammals was also established and similar metabolic pathways to detoxify the chemicals in both groups of animals were demonstrated [40].

G. mellonella larvae can be employed to assess the toxicity of antimicrobial agents and results show a strong correlation to the toxicity as measured in mammals. In an assessment of the relative toxicity of 1,10 phenanthroline, 1,10 phenanthroline-5,6-dione and related copper and silver complexes a strong correlation between the response of G. mellonella larvae and Swiss mice was established [41] (Figure 3). While the rank order of toxicity differed slightly, the most toxic compound in larvae was also the most toxic in mice indicating the potential of the larval system for rapidly, and cost effectively identifying the toxicity of compounds prior to murine testing. All compounds were less toxic than cisplatin in larvae and mice, and also well tolerated in nude mice. Analysis of the in vivo toxicity of ionic liquids (salts containing poorly co-ordinated ions that remain in liquid form below $100{ }^{\circ} \mathrm{C}$ ) in 
G. mellonella larvae revealed a strong correlation to the toxicity as assessed in other invertebrate models (Daphnia magna and C. elegans) and demonstrated that the larval system was a sensitive and reliable in vivo model system [42].

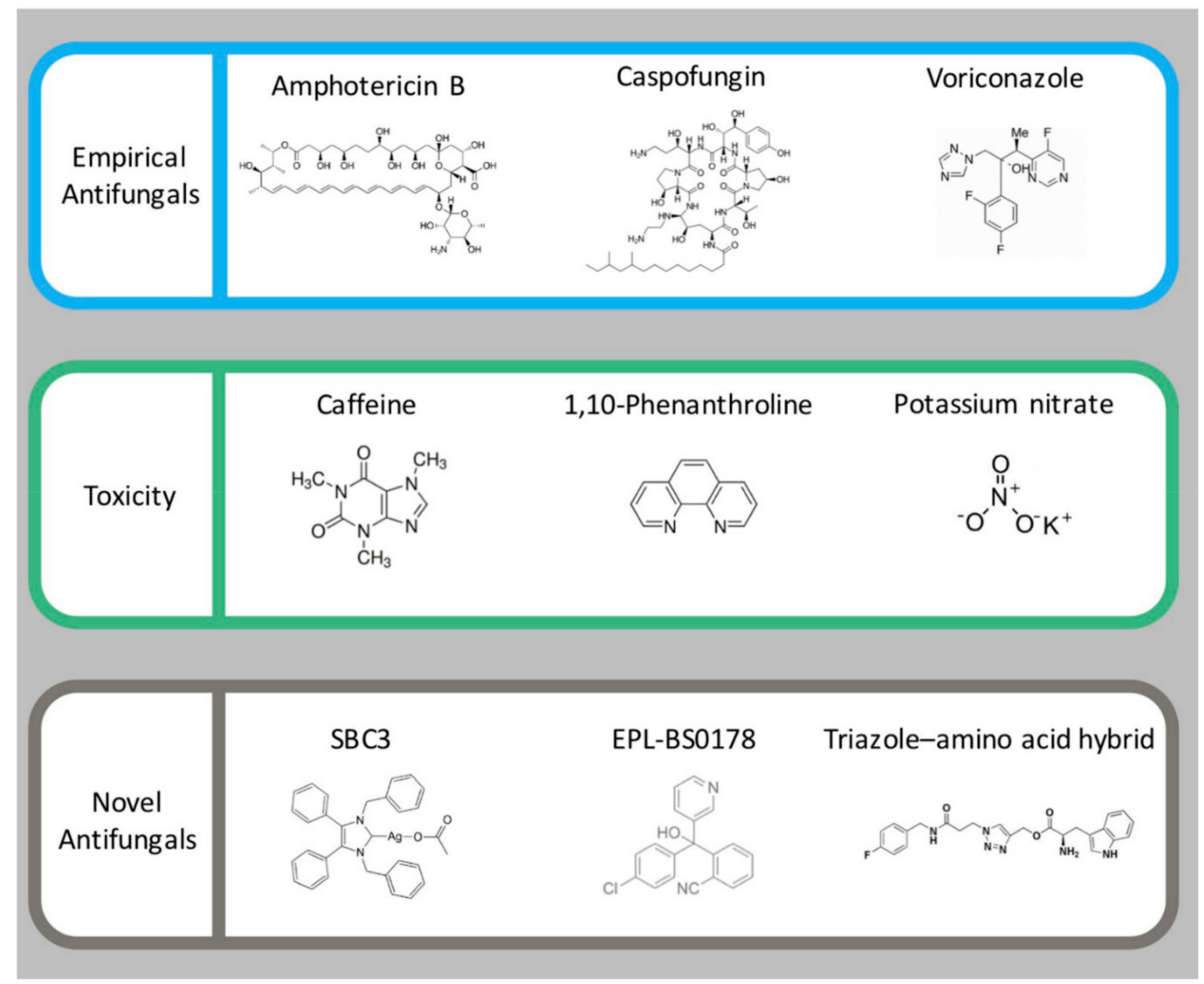

Figure 3. Examples of uses of G. mellonella larvae to assess the in vivo toxicity and efficacy of a range of antifungals and chemical agents. Structures of empirical antifungals amphotericin B [43], caspofungin [44], voriconazole [31]. Chemicals used for toxicity studies; caffeine [9], 1,10-Phenanthroline [41] and potassium nitrate [45]. Novel antifungals; SBC3 (1,3-dibenzyl-4,5-diphenyl-imidazol-2-ylidene silver(I) acetate) [46] active against C. albicans, EPL-BS0178 [47] active against M. mycetomatis and novel triazole-amino acid hybrid (1-(3-(4-fluorobenzylamino)-3-oxopropyl)-1H-1,2,3-triazol-4-yl)methyl 2-amino-3-(1Hindol-3-yl)propanoate) [48].

As well as being suitable to assess the relative in vivo toxicity of compounds, larvae may also be used to study the mode of action of selected compounds and show equivalent results to those found in vertebrates. Administration of potassium nitrate (Figure 3) to G. mellonella larvae produced a response comparable to that observed in mammals and this included an elevated hemocyte density but hemocytes showed reduced fungicidal activity [45]. Larvae administered potassium nitrate also showed alterations in proteins involved in mitochondrial function (e.g., mitochondrial aldehyde dehydrogenase), metabolism (triosephosphate isomerase) and nitrate metabolism (glutathione $S$-transferase), effects also observed in mammals exposed to this compound. Caffeine (Figure 3) administration to G. mellonella larvae resulted in developmental delays (e.g., reduced pupation) and lack of movement which were also observed in Zebra fish embryos [49]. Proteomic analysis of alterations in the brain of larvae administered caffeine indicated increased abundance of proteins 
associated with brain trauma and decreased abundance of proteins implicated in development and protein degradation [9].

A series of novel copper phenanthroline-phenazine cationic complexes which display promising chemotherapeutic potential decrease G. mellonella survival dependent upon enhanced nuclease activity, this is evident at the proteomic level with enrichment of metabolic and detoxification pathways. These results indicate that larvae may be used to assess the tumoricidal activity of novel anti-neoplastic agents [50].

\section{Use of Larvae for Assessing Antifungal Activity In Vivo}

\subsection{Drug Assessment against Pathogenic Yeast}

One of the advantages of using G. mellonella larvae is that the in vivo activity of novel and conventional antifungal agents can be quickly established (Table 2) and this can inform subsequent synthesis of novel derivatives or help establish relative dosage prior to use in mammals. G. mellonella larvae can be rescued (i.e., increased survival and decreased symptoms, e.g., melanization) from a lethal inoculum of $C$. albicans $\left(5 \times 10^{5} /\right.$ larva) by an intra-hemocoel dose of amphotericin B $(1 \mathrm{mg} / \mathrm{kg}$; a dose comparable to clinical dosing levels (maximum $1.5 \mathrm{mg} / \mathrm{kg} /$ day) two hours post-infection (Figure 4). Rowan et al. (2009) demonstrated increased survival of larvae inoculated with C. albicans and followed up 1 and 4 hours later with the novel antifungal compound $\mathrm{Ag}_{2}(\mathrm{mal})(\mathrm{phen})_{3}$ [51]. Prophylactic administration of the antifungal agent also resulted in increased survival and experiments indicated that the agent, as well as exerting inherent antifungal activity, also stimulated the immune response of larvae as measured by increased hemocyte density in larvae and the elevated expression of the gene coding for gallerimycin, which has well established antifungal properties. This immune stimulation effect was also evident when larvae were administered the echinocandin antifungal drug, caspofungin (Figure 3). As well as exhibiting increased survival following C. albicans infection, caspofungin-treated larvae showed increased resistance to Staphylococcus aureus infection although the drug displays no inherent antibacterial activity [44]. Analysis revealed that administration of caspofungin to larvae resulted in increased hemocyte density and an elevation in the expression of genes coding for IMPI and transferrin. A similar immune priming effect inducing protection against $S$. aureus infection in larvae was also observed following administration of micafungin to G. mellonella larvae [52]. When examining the antimicrobial activity of a novel agent, hemocyte densities should be examined 24, 48 and $72 \mathrm{~h}$ post-introduction to control for and determine if the antifungal effect observed is true and not as a result of a stimulated immune response. It was also demonstrated that murine macrophages had enhanced fungicidal activity when pre-treated with micafungin. Prophylactic treatment of mice lead to elevated levels of a number of pro-inflammatory cytokines and enhanced phagocytic ability of neutrophils and macrophages [52].

Table 2. Examples of use of G. mellonella larvae with antifungal agents.

\begin{tabular}{cc}
\hline & Assessment of Antifungal Activity \\
\hline Rowan et al. 2009 [51] & Use of Galleria mellonella larvae to evaluate the in vivo antifungal activity of \\
{$\left[\mathrm{Ag}_{2}(\mathrm{mal})(\mathrm{phen})_{3}\right]$}
\end{tabular}


This immune priming effect can also be induced by administration of $\beta$-glucan, a component of the fungal cell wall which displays no antifungal activity, to larvae. Following $\beta$-glucan administration larvae showed increased resistance to $C$. albicans infection and this was mediated by a dose-dependent cellular and humoral immune response [54]. Administration of high doses of glucan to larvae (e.g., 15-60 $\mu \mathrm{g} /$ larva) induced elevated hemocyte densities, reduced density of yeast cells and increased survival. Larvae also showed elevated abundance of a range of antimicrobial peptides (e.g., archaemetzincin) and immune proteins (e.g., hemolin) [54]. Administration of host derived extracellular nucleic acids to G. mellonella larvae lead to increased expression of antimicrobial peptides and a reduction in hemocyte density. The combined effect resulted in protection of larvae infected by Photorhabdus luminescens indicating that immune stimulation can help overcome a potentially lethal infection [55].

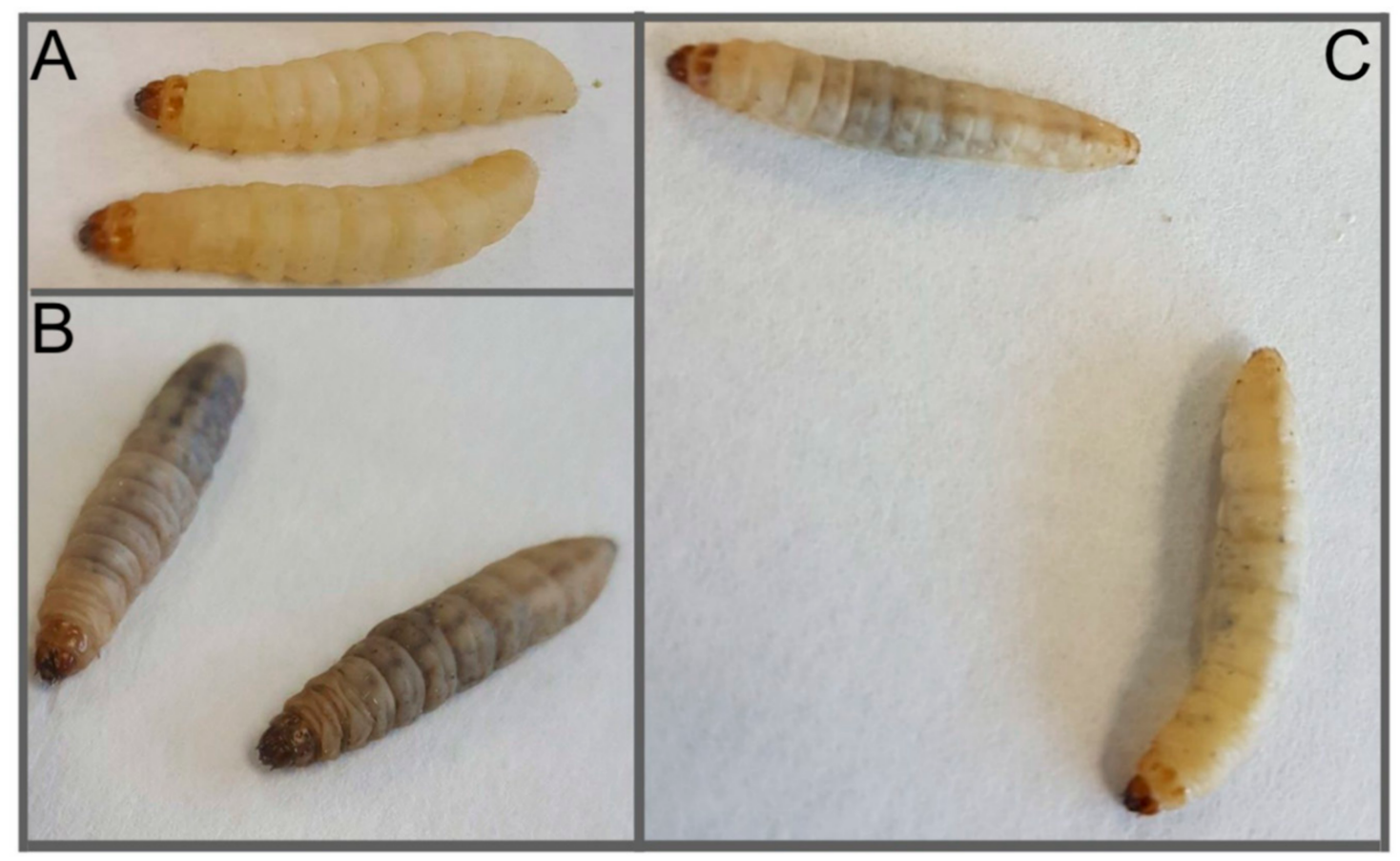

Figure 4. Images of G. mellonella larvae infected with Candida albicans $\left(5 \times 10^{5} /\right.$ larva) $24 \mathrm{~h}$ post-infection. (A) Control larvae administrated PBS $(40 \mu \mathrm{L}),($ B) larvae administrated C. albicans $24 \mathrm{~h}$ post-infection, (C) larvae administrated C. albicans and amphotericin B (1 mg/ kg $2 \mathrm{~h}$ post C. albicans infection) $24 \mathrm{~h}$ post-infection.

These findings are critically important to consider when using G. mellonella larvae, or other insect models, to assess the in vivo efficacy of antifungal drugs. As has been demonstrated the test compound may induce an immune response once introduced into the insect hemocoel. This response may target the invading pathogen and can be mediated by alterations in the hemocyte density and in the abundance of antimicrobial peptides in the insect hemolymph. It is essential to differentiate between the anti-microbial effect due to the increased immune response induced by the compound and the inherent anti-microbial activity of the agent. Interestingly a carbene silver(I) acetate complex demonstrated excellent in vivo anti-Candida activity but was shown not to trigger an immune response in larvae (Figure 3). It was postulated that the relatively small size of the complex was not detected by the larval immune response and thus failed to induce an immune response [46]. A group of novel triazole-amino acids hybrid compounds was assessed for their anti-Candida activity in vitro, and in vivo using G. mellonella larvae. The results showed the compounds did not provoke an immune response in larvae and that administration of compound to larvae resulted in increased survival and reduced yeast cell proliferation [48]. 
Gu et al. (2018) demonstrated that the combination of tetracycline and fluconazole at concentrations equivalent to therapeutic doses in humans rescued larvae from a lethal inoculum of azole resistant C. albicans CA10 compared to fluconazole alone and this was due to a four-fold decrease in fungal burden and fewer infection sites throughout larvae [56]. The Santos groups examined the antifungal efficacy of a range of antifungals on Candida haemulonii complex (C. haemulonii, C. duobushaemulonii and C. haemulonii var. vulnera) and non-albicans species, with the former demonstrating resistance to first line antifungals (e.g., fluconazole, amphotericin B) in G. mellonella larvae [57].

Candida tropicalis dose-dependently killed G. mellonella larvae at both $30{ }^{\circ} \mathrm{C}$ and $37{ }^{\circ} \mathrm{C}$ but larval hemocytes phagocytosed $C$. tropicalis cells slower than those of $C$. neoformans. Amphotericin $\mathrm{B}$, caspofungin (2,4 mg/ kg; comparable to clinical dosing levels), fluconazole and voriconazole all produced protective effects in vivo at clinically relevant doses but amphotericin B $(4 \mathrm{mg} / \mathrm{kg})$ and fluconazole $(3,6$, and $12 \mathrm{mg} / \mathrm{kg})$ significantly decreased fungal burden and melanised nodule formation in larval tissue as evident from tissue sections [31].

The response of G. mellonella larvae to infection with Candida glabrata was studied and infection was shown to be temperature and dose-dependent and the response of the larvae to infection included melanisation and alterations in the hemocyte density. No protection from infection was achieved by administering fluconazole to larvae post-infection, although amphotericin B and caspofungin administration increased larval survival [53]. G. mellonella larvae have also been utilized for assessing the in vivo activity of amphotericin B, flucytosine, and fluconazole following challenge with C. neoformans [27]. Combination therapy consisting of pedalitin and amphotericin B act in synergy against $C$. neoformans infection to improve survival, fungal burden and histopathology in both G. mellonella larvae and in BALB/c mice [58].

Larvae provide a quick and convenient means to assess the potential of novel antifungal therapies prior to murine testing. G. mellonella larvae and mice have been employed to assess the efficacy of antimicrobial peptides in combination with caspofungin for treating C. albicans infections. There was strong agreement between results since treatment of infected larvae and mice with caspofungin and DsS3 (1-16) resulted in enhanced survival of larvae and mice compared to untreated controls and those that received the agents individually [59]. An evaluation of the effect of acetylcholine (ACh) on G. mellonella larvae indicated it enhanced the activity of hemocytes and protected larvae from C. albicans induced infection [60]. ACh inhibited the C. albicans dimorphic switch and biofilm formation and this, together with the elevated immune response, may have prevented disease development. This result indicated the potential of using ACh as either an antifungal agent with direct effect on the yeast or as an immune stimulant in mammals.

\subsection{Drug Assessment against Filamentous Fungi}

G. mellonella larvae have been widely used to study azole resistance in A. fumigatus [61]. Alaczar-Fuoli et al. (2015) demonstrated voriconazole selected for Aspergillus lentulus in mixed infections with $A$. fumigatus, which together respond differentially to larval hemocytes and produce distinct histological features (e.g., melanisation). Larvae did not respond to a therapeutic dose of voriconazole in mixed Aspergillus infection [62]. Haemofungin is a novel synthetic drug-like molecule which causes fungal cell swelling and lysis by inhibiting ferrochelatase, the last enzyme in the haem biosynthetic pathway, and is active at low concentrations against pathogenic moulds and yeast. In larvae, haemofungin is non-toxic up to $22.7 \mathrm{mg} / \mathrm{kg}$. Most interestingly, a concentration of $5.7 \mathrm{mg} / \mathrm{kg}$ haemofungin improved larval survival to A. fumigatus comparable to that of amphotericin (2 mg/kg) [63].

G. mellonella larvae have been used to assess the virulence of amphotericin B resistant and susceptible isolates of Aspergillus tereus and to assess the potential of amphotericin B for the control of infection. The results demonstrated that amphotericin $B$ was active against the fungus but also stimulated the larval immune response [35]. G. mellonella larvae have been utilized to assess the virulence potential of a range of mucormycetes (e.g., Rhizopus spp., Rhizomucor spp., Mucor spp.) and 
demonstrated the virulence potential was strain and infection dose specific. In addition, the ability of the fungus to tolerate oxidative stress was also a critical factor in its ability to cause disease [10]. The in vivo antifungal potential of liposomal amphotericin B, posaconazole, isavuconazole and nystatin against the fungal pathogens was assessed in larvae. Good control of infection was achieved with nystatin and posaconazole, but not with liposomal amphotericin B and isavuconazole [10]. Madurella mycetomatis infection results in the formation of large subcutaneous lesions in humans and antifungal therapy is difficult due to the formation of grains within infected tissue. G. mellonella larvae are susceptible to infection by M. mycetomatis and infected tissue also shows the presence of grains. Larvae have been used to identify potential antifungal therapies for use in humans and highlighted that amphotericin B and terbinafine prolonged larval survival while azoles proved ineffective [43]. A recent study screened 800 compounds and tested the ten most active compounds for antifungal efficacy in larvae against $M$. mycetomatis. Several compounds enhanced survival and/or reduced fungal burden. Fenarimol analogues, especially EPL-BS0178 appeared most potent possibly due to their polarity, permeability and tissue distribution allowing penetration of M. mycetomatis grains in vivo [47].

White nose syndrome is a fungal disease of bats caused by Pseudogymnoascus destructans and this has been responsible for the deaths of millions of bats in North America in recent years. G. mellonella larvae were shown to be susceptible to disease by P. destructans and were used to demonstrate that trifluoperazine and amphotericin B could be used to prevent infection and thus highlighted potential treatment options for use in bats [64].

G. mellonella larvae have been adapted to study the virulence of Fusarium spp and to investigate antifungal therapy and have generated results similar to those obtained from murine studies. Larval killing was dependent on temperature (more rapid at $30^{\circ} \mathrm{C}$ compared to $37^{\circ} \mathrm{C}$ ), strain, inoculum and conidia morphology [65]. Mucor circinelloides is an opportunistic fungal pathogen that commonly infects patients with an aberrant immune status and presents as nasal, facial or subcutaneous necrosis and disseminated disease [66]. Bastidas et al. 2012 found that the immunosuppressive agent rapamycin, possessed antifungal activity mediated by interactions with FKBP12 and a Tor homolog. G. mellonella larvae infected with a lethal dose of $M$. circinelloides R7B were treated with rapamycin ( $33 \mathrm{mg} / \mathrm{kg}$ body weight) and resulted in a $50 \%$ survival rate as compared to the $0 \%$ control after 5 days [67].

Trichosporon species are opportunistic anamorphous basidiomycetes, which cause infections ranging from superficial to systemic in the immunocompromised host and are estimated to be in the top three most common non-Candida yeast infection that cause invasive disease in haematological cancer patients $[68,69]$. Trichosporon asahii, T. asteroides and T. inkin all infected G. mellonella larvae and immunosuppressed mice with species-specific differences. However, significant differences were observed between $T$. asteroids species in mice. Both fluconazole and voriconazole improved survival in G. mellonella and mice amongst the three species examined. However, amphotericin B improved survival in mice but not in larvae [70].

G. mellonella larvae have also been employed to study infection by Paracoccidioides brasiliensis and Paracoccidioides lutzii the main causative agents of paracoccidioidomycosis, an endemic mycosis in South and Central America. Typically, murine studies can take up to 60 days for infection/therapy, with patient treatment lasting up to 18 months, however, results obtained from larvae infected with Paracoccidioides were recorded within 7 days. Larvae were protected from Paracoccidioides infection following amphotericin B or itraconazole at therapeutic doses, which decreased fungal burden in larval tissue [71].

\section{Conclusions}

Larvae of G. mellonella have become popular models for examining the in vivo toxicity and efficacy of antifungal drugs and give a good indication of the likely dose and effect in mammals without the need to use large numbers of mammals in the initial screens. The use of G. mellonella larvae can be extended to study disease development in vivo and to monitor the effects of antifungal agents on 
specific aspects of infection. Larvae are easy to use, inexpensive to purchase, and are free from the legal/ethical restriction that are applied to the use of mammals. The use of G. mellonella larvae in this capacity will never completely remove the need to use mammals in this role, but judicious use of larvae can accelerate the identification of potential therapeutic doses for use in mammals and allow the rapid identification of novel antifungal agents prior to use in mammals.

Funding: This research received no external funding.

Conflicts of Interest: The authors declare no conflict of interest.

\section{References}

1. Kavanagh, K.; Reeves, E.P. Exploiting the potential of insects for in vivo pathogenicity testing of microbial pathogens. FEMS Microbiol. Rev. 2004, 28, 101-112. [CrossRef] [PubMed]

2. Browne, N.; Heelan, M.; Kavanagh, K. An analysis of the structural and functional similarities of insect hemocytes and mammalian phagocytes. Virulence 2013, 4, 597-603. [CrossRef] [PubMed]

3. Fuchs, B.B.; Mylonakis, E. Using non-mammalian hosts to study fungal virulence and host defense. Curr. Opin. Microbiol. 2006, 9, 346-351. [CrossRef] [PubMed]

4. Kemp, M.W.; Massey, R.C. The use of insect models to study human pathogens. Drug Discov. Today Dis. Model. 2007, 4, 105-110. [CrossRef]

5. Arvanitis, M.; Glavis-Bloom, J.; Mylonakis, E. Invertebrate models of fungal infection. Biochim. Biophys. Acta Mol. Basis Dis. 2013, 1832, 1378-1383. [CrossRef] [PubMed]

6. Fuchs, B.B.; O’Brien, E.; El Khoury, J.B.; Mylonakis, E. Methods for using Galleria mellonella as a model host to study fungal pathogenesis. Virulence 2010, 1, 475-482. [CrossRef] [PubMed]

7. Cook, S.M.; McArthur, J.D. Developing Galleria mellonella as a model host for human pathogens. Virulence 2013, 4, 350-353. [CrossRef] [PubMed]

8. Astvad, K.M.T.; Meletiadis, J.; Whalley, S.; Arendrup, M.C. Fluconazole pharmacokinetics in Galleria mellonella larvae and performance evaluation of a bioassay compared to liquid chromatography-tandem mass spectrometry for hemolymph specimens. Antimicrob. Agents Chemother. 2017, 61, e00895-17. [CrossRef] [PubMed]

9. Maguire, R.; Kunc, M.; Hyrsl, P.; Kavanagh, K. Caffeine administration alters the behaviour and development of Galleria mellonella larvae. Neurotoxicol. Teratol. 2017, 64, 37-44. [CrossRef] [PubMed]

10. Maurer, E.; Hörtnagl, C.; Lackner, M.; Grässle, D.; Naschberger, V.; Moser, P.; Segal, E.; Semis, M.; Lass-Flörl, C.; Binder, U. Galleria mellonella as a model system to study virulence potential of mucormycetes and evaluation of antifungal treatment. Med. Mycol. 2018. [CrossRef] [PubMed]

11. Bergin, D.; Reeves, E.P.; Renwick, J.; Frans, B.; Kavanagh, K.; Wientjes, F.B. Superoxide Production in Galleria mellonella Hemocytes: Identification of Proteins Homologous to the NADPH Oxidase Complex of Human Neutrophils Superoxide Production in Galleria mellonella Hemocytes: Identification of Proteins Homologous to the NADPH Ox. Infect. Immun. 2005, 73, 4161-4170. [CrossRef] [PubMed]

12. Renwick, J.; Reeves, E.P.; Wientjes, F.B.; Kavanagh, K. Translocation of proteins homologous to human neutrophil p47phox and p67phox to the cell membrane in activated hemocytes of Galleria mellonella. Dev. Comp. Immunol. 2007, 31, 347-359. [CrossRef] [PubMed]

13. Banville, N.; Fallon, J.; McLoughlin, K.; Kavanagh, K. Disruption of haemocyte function by exposure to cytochalasin $\mathrm{b}$ or nocodazole increases the susceptibility of Galleria mellonella larvae to infection. Microbes Infect. 2011, 13, 1191-1198. [CrossRef] [PubMed]

14. Fallon, J.P.; Reeves, E.P.; Kavanagh, K. The Aspergillus fumigatus toxin fumagillin suppresses the immune response of Galleria mellonella larvae by inhibiting the action of haemocytes. Microbiology 2011, 157, 1481-1488. [CrossRef] [PubMed]

15. Tsai, C.J.-Y.; Loh, J.M.S.; Proft, T. Galleria mellonella infection models for the study of bacterial diseases and for antimicrobial drug testing. Virulence 2016, 7, 214-229. [CrossRef] [PubMed]

16. Mukherjee, K.; Vilcinskas, A. Development and immunity-related microRNAs of the lepidopteran model host Galleria mellonella. BMC Genom. 2014, 15, 705. [CrossRef] [PubMed]

17. Champion, O.L.; Wagley, S.; Titball, R.W. Galleria mellonella as a model host for microbiological and toxin research. Virulence 2016, 7, 840-845. [CrossRef] 
18. Heitmueller, M.; Billion, A.; Dobrindt, U.; Vilcinskas, A.; Mukherjee, K. Epigenetic mechanisms regulate innate immunity against uropathogenic and commensal-like Escherichia coli in the surrogate insect model Galleria mellonella. Infect. Immun. 2017, 85, e00336-17. [CrossRef] [PubMed]

19. Sheehan, G.; Kavanagh, K. Analysis of the early cellular and humoral responses of Galleria mellonella larvae to infection by Candida albicans. Virulence 2018, 9, 163-172. [CrossRef] [PubMed]

20. Cooper, D.; Eleftherianos, I. Memory and specificity in the insect immune system: Current perspectives and future challenges. Front. Immunol. 2017, 8, 539. [CrossRef] [PubMed]

21. Cotter, G.; Doyle, S.; Kavanagh, K. Development of an insect model for the in vivo pathogenicity testing of yeasts. FEMS Immunol. Med. Microbiol. 2000, 27, 163-169. [CrossRef] [PubMed]

22. Brennan, M.; Thomas, D.Y.; Whiteway, M.; Kavanagh, K. Correlation between virulence of Candida albicans mutants in mice and Galleria mellonella larvae. FEMS Immunol. Med. Microbiol. 2002, 34, 153-157. [CrossRef] [PubMed]

23. Slater, J.L.; Gregson, L.; Denning, D.W.; Warn, P.A. Pathogenicity of Aspergillus fumigatus mutants assessed in Galleria mellonella matches that in mice. Med. Mycol. 2011, 49 (Suppl. 1), S107-S113. [CrossRef] [PubMed]

24. Reeves, E.P.; Messina, C.G.M.; Doyle, S.; Kavanagh, K. Correlation between gliotoxin production and virulence of Aspergillus fumigatus in Galleria mellonella. Mycopathologia 2004, 158, 73-79. [CrossRef] [PubMed]

25. O’Hanlon, K.A.; Cairns, T.; Stack, D.; Schrettl, M.; Bignell, E.M.; Kavanagh, K.; Miggin, S.M.; O’Keeffe, G.; Larsen, T.O.; Doyle, S. Targeted disruption of nonribosomal peptide synthetase Pes3 augments the virulence of Aspergillus fumigatus. Infect. Immun. 2011, 79, 3978-3992. [CrossRef] [PubMed]

26. Jacobsen, I.D. Galleria mellonella as a model host to study virulence of Candida. Virulence 2014, 5, $237-239$. [CrossRef] [PubMed]

27. Mylonakis, E.; Moreno, R.; El Khoury, J.B.; Idnurm, A.; Heitman, J.; Calderwood, S.B.; Ausubel, F.M.; Diener, A. Galleria mellonella as a model system to study Cryptococcus neoformans pathogenesis. Infect. Immun. 2005, 73, 3842-3850. [CrossRef] [PubMed]

28. Velagapudi, R.; Hsueh, Y.P.; Geunes-Boyer, S.; Wright, J.R.; Heitman, J. Spores as infectious propagules of Cryptococcus neoformans. Infect. Immun. 2009, 77, 4345-4355. [CrossRef] [PubMed]

29. London, R.; Orozco, B.S.; Mylonakis, E. The pursuit of cryptococcal pathogenesis: Heterologous hosts and the study of cryptococcal host-pathogen interactions. FEMS Yeast Res. 2006, 6, 567-573. [CrossRef] [PubMed]

30. McClelland, E.E.; Ramagopal, U.A.; Rivera, J.; Cox, J.; Nakouzi, A.; Prabu, M.M.; Almo, S.C.; Casadevall, A. A Small Protein Associated with Fungal Energy Metabolism Affects the Virulence of Cryptococcus neoformans in Mammals. PLoS Pathog. 2016, 12, e1005849. [CrossRef] [PubMed]

31. Mesa-Arango, A.C.; Forastiero, A.; Bernal-Martínez, L.; Cuenca-Estrella, M.; Mellado, E.; Zaragoza, O. The non-mammalian host Galleria mellonella can be used to study the virulence of the fungal pathogen Candida tropicalis and the efficacy of antifungal drugs during infection by this pathogenic yeast. Med. Mycol. 2013, 51, 461-472. [CrossRef] [PubMed]

32. Borman, A.M.; Szekely, A.; Johnson, E.M. Comparative Pathogenicity of United Kingdom Isolates of the Emerging Pathogen Candida auris and Other Key Pathogenic Candida Species. mSphere 2016, 1, e00189-16. [CrossRef] [PubMed]

33. St. Leger, R.J.; Screen, S.E.; Shams-Pirzadeh, B. Lack of host specialization in Aspergillus flavus. Appl. Environ. Microbiol. 2000, 66, 320-324. [CrossRef] [PubMed]

34. Navarro-Velasco, G.Y.; Prados-Rosales, R.C.; Ortíz-Urquiza, A.; Quesada-Moraga, E.; Di Pietro, A. Galleria mellonella as model host for the trans-kingdom pathogen Fusarium oxysporum. Fungal Genet. Biol. 2011, 48, 1124-1129. [CrossRef] [PubMed]

35. Maurer, E.; Browne, N.; Surlis, C.; Jukic, E.; Moser, P.; Kavanagh, K.; Binder, U. Galleria mellonella as a host model to study Aspergillus terreus virulence and amphotericin B resistance. Virulence 2015, 6, 591-598. [CrossRef] [PubMed]

36. Thomaz, L.; García-Rodas, R.; Guimarães, A.J.; Taborda, C.P.; Zaragoza, O.; Nosanchuk, J.D. Galleria mellonella as a model host to study Paracoccidioides Lutzii and Histoplasma Capsulatum. Virulence 2013, 4, 139-146. [CrossRef] [PubMed]

37. Sheehan, G.; Clarke, G.; Kavanagh, K. Characterisation of the cellular and proteomic response of Galleria mellonella larvae to the development of invasive aspergillosis. BMC Microbiol. 2018, 18, 63. [CrossRef] [PubMed] 
38. Maguire, R.; Duggan, O.; Kavanagh, K. Evaluation of Galleria mellonella larvae as an in vivo model for assessing the relative toxicity of food preservative agents. Cell Biol. Toxicol. 2016, 32, 209-216. [CrossRef] [PubMed]

39. Allegra, E.; Titball, R.W.; Carter, J.; Champion, O.L. Galleria mellonella larvae allow the discrimination of toxic and non-toxic chemicals. Chemosphere 2018, 198, 469-472. [CrossRef] [PubMed]

40. Hamamoto, H.; Tonoike, A.; Narushima, K.; Horie, R.; Sekimizu, K. Silkworm as a model animal to evaluate drug candidate toxicity and metabolism. Comp. Biochem. Physiol. C Toxicol. Pharmacol. 2009, 149, 334-339. [CrossRef] [PubMed]

41. McCann, M.; Santos, A.L.S.; Da Silva, B.A.; Romanos, M.T.V.; Pyrrho, A.S.; Devereux, M.; Kavanagh, K.; Fichtner, I.; Kellett, A. In vitro and in vivo studies into the biological activities of 1,10-phenanthroline, 1,10-phenanthroline-5,6-dione and its copper(II) and silver(I) complexes. Toxicol. Res. 2012, 1, 47-54. [CrossRef]

42. Megaw, J.; Thompson, T.P.; Lafferty, R.A.; Gilmore, B.F. Galleria mellonella as a novel in vivo model for assessment of the toxicity of 1-alkyl-3-methylimidazolium chloride ionic liquids. Chemosphere 2015, 139, 197-201. [CrossRef] [PubMed]

43. Kloezen, W.; Parel, F.; Brüggemann, R.; Asouit, K.; Helvert-van Poppel, M.; Fahal, A.; Mouton, J.; van de Sande, W. Amphotericin B and terbinafine but not the azoles prolong survival in Galleria mellonella larvae infected with Madurella mycetomatis. Med. Mycol. 2017, 1, 469-478. [CrossRef] [PubMed]

44. Kelly, J.; Kavanagh, K. Caspofungin primes the immune response of the larvae of Galleria mellonella and induces a non-specific antimicrobial response. J. Med. Microbiol. 2011, 60, 189-196. [CrossRef] [PubMed]

45. Maguire, R.; Kunc, M.; Hyrsl, P.; Kavanagh, K. Analysis of the acute response of Galleria mellonella larvae to potassium nitrate. Comp. Biochem. Physiol. Part C Toxicol. Pharmacol. 2017, 195, 44-51. [CrossRef] [PubMed]

46. Browne, N.; Hackenberg, F.; Streciwilk, W.; Tacke, M.; Kavanagh, K. Assessment of in vivo antimicrobial activity of the carbene silver(I) acetate derivative SBC3 using Galleria mellonella larvae. BioMetals 2014, 27, 745-752. [CrossRef] [PubMed]

47. Lim, W.; Melse, Y.; Konings, M.; Phat Duong, H.; Eadie, K.; Laleu, B.; Perry, B.; Todd, M.H.; Ioset, J.R.; van de Sande, W.W.J. Addressing the most neglected diseases through an open research model: The discovery of fenarimols as novel drug candidates for eumycetoma. PLoS Negl. Trop. Dis. 2018, 12, e0006437. [CrossRef] [PubMed]

48. Aneja, B.; Irfan, M.; Kapil, C.; Jairajpuri, M.A.; Maguire, R.; Kavanagh, K.; Rizvi, M.M.A.; Manzoor, N.; Azam, A.; Abid, M. Effect of novel triazole-amino acid hybrids on growth and virulence of Candida species: In vitro and in vivo studies. Org. Biomol. Chem. 2016, 14, 10599-10619. [CrossRef] [PubMed]

49. Chen, Y.H.; Huang, Y.H.; Wen, C.C.; Wang, Y.H.; Chen, W.L.; Chen, L.C.; Tsay, H.J. Movement disorder and neuromuscular change in zebrafish embryos after exposure to caffeine. Neurotoxicol. Teratol. 2008, 30, 440-447. [CrossRef] [PubMed]

50. Rochford, G.; Molphy, Z.; Browne, N.; Surlis, C.; Devereux, M.; McCann, M.; Kellett, A.; Howe, O.; Kavanagh, K. In-vivo evaluation of the response of Galleria mellonella larvae to novel copper(II) phenanthroline-phenazine complexes. J. Inorg. Biochem. 2018, 186, 135-146. [CrossRef] [PubMed]

51. Rowan, R.; Moran, C.; McCann, M.; Kavanagh, K. Use of Galleria mellonella larvae to evaluate the in vivo anti-fungal activity of $\left[\mathrm{Ag}_{2}(\mathrm{mal})(\mathrm{phen})_{3}\right]$. BioMetals 2009, 22, 461-467. [CrossRef] [PubMed]

52. Fuchs, B.B.; Li, Y.; Li, D.; Johnston, T.; Hendricks, G.; Li, G.; Rajamuthiah, R.; Mylonakis, E. Micafungin Elicits an Immunomodulatory Effect in Galleria mellonella and Mice. Mycopathologia 2016, 181, 17-25. [CrossRef] [PubMed]

53. Ames, L.; Duxbury, S.; Pawlowska, B.; Ho, H.L.; Haynes, K.; Bates, S. Galleria mellonella as a host model to study Candida glabrata virulence and antifungal efficacy. Virulence 2017, 8, 1909-1917. [CrossRef] [PubMed]

54. Mowlds, P.; Coates, C.; Renwick, J.; Kavanagh, K. Dose-dependent cellular and humoral responses in Galleria mellonella larvae following $\beta$-glucan inoculation. Microbes Infect. 2010, 12, 146-153. [CrossRef] [PubMed]

55. Altincicek, B.; Stotzel, S.; Wygrecka, M.; Preissner, K.T.; Vilcinskas, A. Host-Derived Extracellular Nucleic Acids Enhance Innate Immune Responses, Induce Coagulation, and Prolong Survival upon Infection in Insects. J. Immunol. 2008, 181, 2705-2712. [CrossRef] [PubMed]

56. Gu, W.; Yu, Q.; Yu, C.; Sun, S. In vivo activity of fluconazole/tetracycline combinations in Galleria mellonella with resistant Candida albicans infection. J. Glob. Antimicrob. Resist. 2018, 13, 74-80. [CrossRef] [PubMed] 
57. Silva, L.N.; Campos-Silva, R.; Ramos, L.S.; Trentin, D.S.; Macedo, A.J.; Branquinha, M.H.; Santos, A.L.S. Virulence of Candida haemulonii complex in Galleria mellonella and efficacy of classical antifungal drugs: A comparative study with other clinically relevant non-albicans Candida species. FEMS Yeast Res. 2018, 18. [CrossRef] [PubMed]

58. Sangalli-Leite, F.; Scorzoni, L.; da Silva, J.D.; de Oliveira, H.C.; de Lacorte Singulani, J.; Gullo, F.P.; da Silva, R.M.; Regasini, L.O.; da Silva, D.H.; da Silva Bolzani, V.; et al. Synergistic effect of pedalitin and amphotericin B against Cryptococcus neoformans by in vitro and in vivo evaluation. Int. J. Antimicrob. Agents 2016, 48, 504-511. [CrossRef] [PubMed]

59. MacCallum, D.M.; Desbois, A.P.; Coote, P.J. Enhanced efficacy of synergistic combinations of antimicrobial peptides with caspofungin versus Candida albicans in insect and murine models of systemic infection. Eur. J. Clin. Microbiol. Infect. Dis. 2013, 32, 1055-1062. [CrossRef] [PubMed]

60. Rajendran, R.; Borghi, E.; Falleni, M.; Perdoni, F.; Tosi, D.; Lappin, D.F.; O’Donnell, L.; Greetham, D.; Ramage, G.; Nile, C. Acetylcholine protects against Candida albicans infection by inhibiting biofilm formation and promoting hemocyte function in a Galleria mellonella infection model. Eukaryot. Cell 2015, 14, 834-844. [CrossRef] [PubMed]

61. Gomez-Lopez, A.; Forastiero, A.; Cendejas-Bueno, E.; Gregson, L.; Mellado, E.; Howard, S.J.; Livermore, J.L.; Hope, W.W.; Cuenca-Estrella, M. An invertebrate model to evaluate virulence in Aspergillus fumigatus: The role of azole resistance. Med. Mycol. 2014, 52, 311-319. [CrossRef] [PubMed]

62. Alcazar-Fuoli, L.; Buitrago, M.; Gomez-Lopez, A.; Mellado, E. An alternative host model of a mixed fungal infection by azole susceptible and resistant Aspergillus spp strains. Virulence 2015, 6, 376-384. [CrossRef] [PubMed]

63. Ben Yaakov, D.; Rivkin, A.; Mircus, G.; Albert, N.; Dietl, A.M.; Kovalerchick, D.; Carmeli, S.; Haas, H.; Kontoyiannis, D.P.; Osherov, N. Identification and characterization of haemofungin, a novel antifungal compound that inhibits the final step of haem biosynthesis. J. Antimicrob. Chemother. 2016, 71, 946-952. [CrossRef] [PubMed]

64. Beekman, C.; Meckler, L.; Kim, E.; Bennett, R.J. Galleria mellonella as an Insect Model for P. destructans, the Cause of White-Nose Syndrome in Bats. PLOS ONE 2018, 13, e0201915. [CrossRef] [PubMed]

65. Coleman, J.J.; Muhammed, M.; Kasperkovitz, P.V.; Vyas, J.M.; Mylonakis, E. Fusarium pathogenesis investigated using Galleria mellonella as a heterologous host. Fungal Biol. 2011, 115, 1279-1289. [CrossRef] [PubMed]

66. Rogers, T.R. Treatment of zygomycosis: Current and new options. J. Antimicrob. Chemother. 2008, 61, 35-40. [CrossRef] [PubMed]

67. Bastidas, R.J.; Shertz, C.A.; Lee, S.C.; Heitman, J.; Cardenas, M.E. Rapamycin exerts antifungal activity in vitro and in vivo against mucor circinelloides via FKBP12-dependent inhibition of tor. Eukaryot. Cell 2012, 11, 270-281. [CrossRef] [PubMed]

68. Ribeiro, M.A.; Alastruey-Izquierdo, A.; Gomez-Lopez, A.; Rodriguez-Tudela, J.L.; Cuenca-Estrella, M. Molecular identification and susceptibility testing of Trichosporon isolates from a Brazilian hospital. Rev. Iberoam. Micol. 2008, 25, 221-225.

69. Colombo, A.L.; Padovan, A.C.B.; Chaves, G.M. Current knowledge of trichosporon spp. and trichosporonosis. Clin. Microbiol. Rev. 2011, 24, 682-700. [CrossRef] [PubMed]

70. Mariné, M.; Bom, V.L.P.; de Castro, P.A.; Winkelstroter, L.K.; Ramalho, L.N.; Brown, N.A.; Goldman, G.H. The development of animal infection models and antifungal efficacy assays against clinical isolates of Trichosporon asahii, T. asteroides and T. inkin. Virulence 2015, 6, 476-486. [CrossRef] [PubMed]

71. de Lacorte Singulani, J.; Scorzoni, L.; de Paula e Silva, A.C.A.; Fusco-Almeida, A.M.; Mendes-Giannini, M.J.S. Evaluation of the efficacy of antifungal drugs against Paracoccidioides brasiliensis and Paracoccidioides lutzii in a Galleria mellonella model. Int. J. Antimicrob. Agents 2016, 48, 292-297. [CrossRef] [PubMed]

(C) 2018 by the authors. Licensee MDPI, Basel, Switzerland. This article is an open access article distributed under the terms and conditions of the Creative Commons Attribution (CC BY) license (http://creativecommons.org/licenses/by/4.0/). 